\title{
ANÁLISE DOS MÉTODOS DE ESTOCAGEM NOS BANCOS DE LEITE DA GRANDE NATAL/RN
}

\author{
Whanderson Maxwell Silva da Cunha (INSTITUTO FEDERAL DE CIÊNCIA E \\ TECNOLOGIA DO RIO GRANDE DO NORTE - IFRN) wanderson.s@escolar.ifrn.edu \\ Dayse Chagas Bezerra (INSTITUTO FEDERAL DE CIÊNCIA E TECNOLOGIA DO \\ RIO GRANDE DO NORTE - IFRN) dayse.chagas@ hotmail.com \\ Elizandra Louise de Sousa (INSTITUTO FEDERAL DE CIÊNCIA E TECNOLOGIA DO \\ RIO GRANDE DO NORTE - IFRN) elizandrasousa406@gmail.com \\ Roberta Stefanny Gomes da Silva (INSTITUTO FEDERAL DE CIÊNCIA E \\ TECNOLOGIA DO RIO GRANDE DO NORTE - IFRN) robertastefanny6@gmail.com
}

\section{Resumo}

A pesquisa tem caráter qualitativo e, através de entrevistas, teve como objetivo explorar os métodos de estocagem utilizados pelos bancos de leite entrevistados, analisando a eficiência do método administrativo das organizações e tendo como foco o estudo do método de estocagem PVPS no caso em questão. Nessa perspectiva, evidenciou-se uma incapacidade, presente no atual sistema de atendimento, no suprimento da demanda de leite requerido pelos pacientes, bem como gargalos sustentados pelo sistema de organização dos setores visitados. Assim, este artigo propõe sugestões para o conseguimento de uma melhor otimização dos processos envolvendo a gestão de pessoas, dados e leite materno.

Palavras-Chaves: Métodos de estocagem; Banco de leite; Estoque; Gestão.

\section{Introdução}

Desde a Revolução industrial - período no qual grande parte da mão de obra humana foi substituída por máquinas -, até a atualidade, percebe-se que houve um alarmante aumento no desenvolvimento da visão capitalista perante a população no âmbito mundial. O revolucionamento industrial mudou a vida da humanidade e deu início a uma nova conjuntura e comportamento social.

Com a Era industrial, vêm os danos à saúde humana, gerados pela constante poluição do meio ambiente, devido a fatores como, por exemplo, a queima de combustíveis fósseis. Isso ocasiona 
um grande problema mundial: o aquecimento global, aumento da temperatura do planeta que se dá pelo agravamento do fenômeno conhecido como efeito estufa - que consiste no aprisionamento de $\mathrm{CO}_{2}$ (dióxido de carbono) na atmosfera terrestre, que pode ser emitido de diversas formas, a principal forma de emissão de $\mathrm{CO}_{2}$ é a combustão de materiais e combustíveis fósseis.

Juntamente ao aquecimento global, vem à tona o alastramento de diversas epidemias geradas pela proliferação de novos tipos de vírus, decorrentes da condição suscetível do planeta. Por conta da contínua aparição de novos vírus, é importante prevenir-se com a vacinação para hostilizar e, assim, erradicar o surgimento e aquisição de doenças. Isso vale, principalmente, para crianças e recém-nascidos (que são alvos do grupo de risco, pois possuem uma maior vulnerabilidade imunológica).

Um composto muito importante, que ajuda no desenvolvimento dos sistemas fisio e imunológico de crianças recém-nascidas - por proporcionar nutrientes que ajudam a prevenir e combater doenças tanto na fase infantil quanto na vida adulta -, é o leite materno. A amamentação (seja de forma convencional ou com leite doado) fornece os nutrientes necessários para o desenvolvimento físico, mental e cognitivo dos indivíduos, principalmente para recém-nascidos de até 6 meses.

O leite materno é responsável por cerca de 40 a $55 \%$ da energia da criança, fornece vitaminas essenciais, como: A, D, E e K, e desenvolve vantagens imunológicas. No caso de leite materno doado, o processamento da substância deve ser roteirizado e efetuado de maneira eficiente, de modo que esteja pronto e disponível para o consumo, pois se trata de um importante fornecedor de energia e saúde para recém-nascidos.

Diante de uma visão operacional, surge a necessidade do uso de estoques para auxiliar o processamento do leite materno. Para o processamento do leite de forma precisa, torna-se indispensável o uso de estoques, chamados bancos de leite. Com o propósito de correta administração e tratamento dos bancos de leite materno, faz-se necessário a preparação do estoque com algumas particularidades, como: temperatura regularizada, local higienizado, a necessidade de um método de estocagem adequado etc.

Evidenciando a importância do leite materno, este artigo tem o objetivo de analisar organizações do tipo maternidade localizadas na Grande Natal, Rio Grande do Norte. A pesquisa tem foco em duas das principais maternidades da cidade e busca analisar e 
compreender a funcionalidade e processamento das atividades de estocagem, bem como a administração de bancos de leite nas maternidades.

Planeja-se a obtenção de resultados através da realização de pesquisas qualitativas, entrevistas e observação de informações desses bancos de leite, como: o giro de estoque, o método de estocagem utilizado na armazenagem do leite e o tipo de estoque utilizado, ou seja, o tratamento da substância no processo de armazenagem. Dessa forma, a pesquisa viabiliza o estudo do método de estocagem utilizado pelas organizações e a investigação da eficiência do método na administração dos bancos de leite, objetivando o estudo do método estocagem PVPS no caso em questão.

\section{Referencial teórico}

\subsection{Estoques}

De acordo com Fernandes (1984), pode-se definir estoques como qualquer tipo de material que a empresa utiliza para a geração de lucro ou para o fornecimento de matéria prima no processo produtivo. Entende-se também por estoques, todos os bens que, de forma geral, estão num espaço físico e fazem parte de um processo improdutivo, sendo armazenados por um determinado tempo.

Entende-se por estoques quaisquer quantidades de bens físicos que sejam conservados, de forma improdutiva, por algum intervalo de tempo; constituem estoques tanto, os produtos acabados que aguardam venda ou despacho, como matérias primas e componentes que aguardam utilização na produção. (MOREIRA, 1996, p. 463).

Os estoques são espaços essenciais para empresas, pois são responsáveis por garantir o correto funcionamento da organização, auxiliando-a na realização de suas atividades e fornecendo estabilidade nas operações, e são representados como uma necessidade real dentro das empresas.

À frente de uma visão operacional, surge a necessidade do uso de estoques, pois, consoante a Ballou (1993), estoques são acúmulos de matérias-primas, insumos, componentes, produtos em processo e produtos acabados que aparecem nos diversos pontos dos canais logísticos e de produção na empresa. Existem diferentes tipos de demanda, logo, é necessário que existam diferentes tipos de estoques e diferentes métodos para a atividade de estocagem, cada um com sua particularidade. 
Mesmo que grande parte do capital da maioria das organizações esteja investido na atividade de estocagem, é importante destacar que é uma prática essencial para o funcionamento da organização. Segundo Ballou (1993), estoques têm a função de regular o fluxo de materiais, servindo como amortecedor na diferença entre entradas e saídas de materiais. Os estoques são altamente custosos para as empresas, apresentando uma absorção de 30 a $65 \%$ dos custos logísticos, mas são necessários.

O estoque pode ser considerado um procedimento logístico complexo, pois, muitas vezes, têm que comportar vários tipos de materiais diferentes de forma específica, dependendo da necessidade que os armazenados itens possuem. As situações e complexidade de estocagem variam de produto para produto, dependendo de suas características, como: vida útil, necessidade de refrigeração, entre outros fatores. Conforme Ballou (1996), a estocagem de produtos deve ser feita de maneira benéfica ao emissor (empresa / fornecedor do serviço) e ao receptor (cliente / pessoa física que utiliza do serviço).

\subsection{Métodos de estocagem}

Devido a grande diferença de demanda e serviços ofertados pelas empresas, surge a necessidade de utilizar diferentes métodos para a gestão dos estoques. É preciso conciliar o método de administração do estoque com a real necessidade da organização, analisando qual é o método mais adequado para o controle do estoque e adaptando-o à realidade da organização, de maneira a garantir que os estoques sejam consumidos de maneira adequada ao propósito da organização, garantindo-os qualidade. Os métodos de gerenciamento de estoque têm por base o controle contínuo dos materiais e produtos na estocagem.

A administração de materiais merece uma atenção especial por parte dos administradores das instituições (tanto públicas, como privadas), porque essas operações refletem positiva ou negativamente nas empresas (POZO, 2001 Apud VAGO, 2013).

Dentre os principais métodos de estocagem de materiais estão: o PEPS (o Primeiro que Entra é o Primeiro que sai); o UEPS (o Último a Entrar é o Primeiro a Sair); e o PVPS (o Primeiro a Vencer é Primeiro a Sair). Que serão apresentados e explicados mais claramente nos subtítulos a seguir.

\subsubsection{Método P.E.P.S (FIFO)}


A sigla P.E.P.S. significa: Primeiro a entrar, Primeiro a sair (First In, First Out). A avaliação do estoque por este método é feita pela ordem cronológica de entradas de materiais. Primeiramente, irá sair o material que primeiro integrou o estoque, sendo substituído pela mesma ordem cronológica que foi recebido. Esse método serve para a valorização dos materiais estocados, evitando riscos de deterioração e obsolescência dos mesmos (DIAS, 2010).

Nesse método os itens que saem primeiro do estoque são valorizados de acordo com sua primeira entrada, dessa forma, os itens que permanecem armazenados são valorizados de acordo com a sua última entrada (ALMEIDA, 2010).

\subsubsection{Método U.E.P.S (LIFO)}

A sigla UEPS significa: Último a entrar Primeiro a Sair (Last in, First out). De acordo com Dias (2010), esse método avaliativo considera que devem, em primeiro lugar, sair os últimos itens que deram entrada no estoque, o que faz com que o saldo seja avaliado ao das últimas entradas. É o método recomendado para períodos inflacionários, pois uniformiza o preço dos produtos em estoque para venda no mercado consumidor.

Para Almeida (2010), esse método funciona de modo que as quantidades ficam em estoque são valorizadas pelos primeiros custos unitários e as que saem são valorizadas pelos últimos custos unitários. Portanto, método baseia-se teoricamente na premissa de que o estoque de reserva é o equivalente ao ativo fixo.

\subsubsection{Método P.V.P.S (FEFO)}

A sigla PVPS significa: Primeiro que Vence, Primeiro que Sai (First Expire, First Out). Este método é utilizado para produtos que possuem data de validade. A ideia central deste método é que os produtos com prazos mais próximos ao vencimento devem ser os primeiros a serem utilizados, mesmo que suas entradas no estoque sejam posteriores à de lotes que já estavam estocados. A disposição dos produtos deve obedecer a data de fabricação, sendo que os produtos de fabricação mais antiga são posicionados a serem consumidos em primeiro lugar. (MADEIRA e FERRÃO, 2002 Apud SALVETTI, L., 2012. p.35).

Para utilização do método PVPS é necessário um controle mais rígido do estoque, pois é preciso ter atenção a data de validades dos produtos estocados. Para auxílio na utilização deste método é recomendado a utilização de planilhas, softwares de controle ou etiquetas indicadoras de ordem de uso do produto, em prol de garantir a correta gestão do estoque com base no método PVPS (ALMEIDA, 2010). Pode-se pensar ainda na organização física, em prateleiras ou pallets de forma prática e lógica. 


\section{Metodologia}

A pesquisa foi realizada em duas das principais maternidades da cidade de Natal, Rio Grande do Norte: Maternidade Escola Januário Cicco e Hospital Geral do Santa Catarina. Para a efetivação da pesquisa empregou-se um método de pesquisa qualitativo e utilizou-se de perguntas objetivas (presentes no questionário, apresentado no item 3.1.2) a respeito de processos realizados nas maternidades em evidência, como: coleta, armazenagem, tratamento, processamento e distribuição do leite materno.

Este artigo trata de analisar os bancos de leite de maternidades em evidência, utilizando uma abordagem logística a respeito do processamento e estocagem do composto nos bancos de leite. Para o desenvolvimento e realização da pesquisa, e para a obtenção de dados, foram utilizados de recursos como matérias informativas, artigos científicos e visita de campo às maternidades supracitadas.

\subsection{Roteiro de pesquisa}

O roteiro elaborado foi utilizado como suporte de orientação da pesquisa, seguindo as etapas metodológicas e as perguntas presentes no questionário, ambas apresentadas nos itens 3.1.1. e 3.1 .2 , respectivamente.

\subsubsection{Etapas metodológicas}

Para a realização da pesquisa, foi feita uma subdivisão de etapas metodológicas que dividem os processos do estudo:

a) Escolha do objeto de estudo;

b) Iniciação à pesquisa. Averiguação e levantamento de dados qualitativos;

c) Visita às maternidades e recolhimento de dados que agreguem valor à pesquisa. Nas visitas realizadas às organizações foi aplicado um questionário, elaborado previamente, com perguntas relevantes à conclusão da pesquisa;

d) Analisar e estudar o método de estocagem utilizado nas maternidades e procurar possíveis erros logísticos presentes no processamento do leite e, se caso for encontrado algum provável erro logístico, bem como fornecer possíveis soluções para o problema encontrado;

e) Investigar o método de estocagem utilizado pelas maternidades. Estudar o 
funcionamento e administração dos bancos de leite pelo método de estocagem PVPS.

\subsubsection{Questionário aplicado nas entrevistas às maternidades}

O questionário elaborado e aplicado teve como objetivo auxiliar e orientar a pesquisa no quesito de coleta de dados. O questionário da pesquisa está presente no quadro 1:

Quadro 1 - Questionário aplicado em dois dos principais bancos de leite de Natal/RN

\begin{tabular}{|c|}
\hline Questionário aplicado nas en trevistas às maternidades \\
\hline Pergunta 1: quantos litros de leite são utilizados por dia? \\
\hline $\begin{array}{l}\text { Pergunta 2: qual é o método utilizado no sistema de controle de estoque? É processado, } \\
\text { primeiramente, os leites que chegam ao estoque primeiro, por último, ou é organizado por } \\
\text { prazos devalidade? }\end{array}$ \\
\hline $\begin{array}{l}\text { Pergunta 3: o estoque é abastecido diariamente? E quando abastecido, com } \\
\text { aproximadamente quantos litros de leite? }\end{array}$ \\
\hline $\begin{array}{l}\text { Pergunta 4: como o leite é processado e armazenado nos bancos de leite? O estoque é } \\
\text { organizado especificamente para estocagem leite? Como é organizado o banco de leite e } \\
\text { quais são as condições do espaço físico em que o leite fica armazenado (questões de } \\
\text { estocagem e proteção)? }\end{array}$ \\
\hline $\begin{array}{l}\text { Pergunta } 5 \text { : há algum tipo de manutenção feita na estrutura física desse estoque? E quando } \\
\text { é feita, onde fica o leite durante essa manutenção? }\end{array}$ \\
\hline Pergunta 6: o banco de leite precisa, em média, de quantas pessoas para cuidar do estoque? \\
\hline $\begin{array}{l}\text { Pergunta } 7 \text { : todas as pessoas que trabalham na instituição têm acesso e podem manusear o } \\
\text { estoque? }\end{array}$ \\
\hline $\begin{array}{l}\text { Pergunta 8: você pode identificar problemas de infraestrutura ou funcionamento no banco } \\
\text { de leite? }\end{array}$ \\
\hline $\begin{array}{l}\text { Pergunta 9: você pode identificar algum problema em relação a estocagem do leite na } \\
\text { organização? }\end{array}$ \\
\hline
\end{tabular}

Fonte: Autores, 2019 


\section{Resultados obtidos}

A partir das entrevistas, verificou-se a existência de um padrão de processos na administração dos bancos de leite, constatou-se que esse padrão ocorre por ser considerada uma maneira de gerência que agrega um padrão de qualidade na conclusão das atividades exercidas pelas maternidades. Dessa forma, os processos que ocorrem na manipulação do leite nos bancos foram analisados, registrados e serão apresentados nesse item em forma de um único quadro que mostra as diferenças e semelhanças das instituições nas respostas às perguntas contidas no questionário (apresentado no Quadro 1).

Quadro 2 - Respostas para o questionário do quadro 1 recolhidas em dois dos principais bancos de leite de Natal/RN

\begin{tabular}{|c|c|c|}
\hline & \multicolumn{2}{|l|}{$\begin{array}{l}\text { Resposta às perguntas presentes } \\
\text { no questionário do Quadro } 1\end{array}$} \\
\hline & Hospital Geral do Santa Catarina & Maternidade Escola Januário Cicco \\
\hline $\begin{array}{l}\text { Resposta à } \\
\text { pergunta 1: }\end{array}$ & \multicolumn{2}{|c|}{$\begin{array}{l}\text { Na grande maioria dos dias são disponibilizados } 8 \text { litros de leite para } \\
\text { outros setores da instituição. }\end{array}$} \\
\hline $\begin{array}{l}\text { Resposta à } \\
\text { pergunta 2: }\end{array}$ & \multicolumn{2}{|c|}{$\begin{array}{l}\text { PVPS (primeiro que entre é o primeiro que sai), pois o leite possui vida } \\
\text { útil. }\end{array}$} \\
\hline $\begin{array}{l}\text { Resposta à } \\
\text { pergunta 3: }\end{array}$ & $\begin{array}{l}\text { O banco de leite é abastecido } \\
\text { diariamente com doações das mães } \\
\text { das crianças que estão internadas } \\
\text { ou de doadoras que não possuem } \\
\text { ligação parental com os recém- } \\
\text { nascidos que receberão o leite. São } \\
\text { coletados, em média, } 3 \text { litros por } \\
\text { dia. }\end{array}$ & $\begin{array}{l}\text { O banco de leite é abastecido } \\
\text { diariamente com doações das mães } \\
\text { das crianças que estão internadas ou } \\
\text { de doadoras que não possuem ligação } \\
\text { parental com os recém-nascidos que } \\
\text { receberão o leite. São coletados, em } \\
\text { média } 6 \text { litros por dia. }\end{array}$ \\
\hline $\begin{array}{l}\text { Resposta à } \\
\text { pergunta 4: }\end{array}$ & \multicolumn{2}{|c|}{$\begin{array}{l}\text { O processamento do leite pelas maternidades segue o padrão de } \\
\text { tratamento descrito a seguir: } \\
\text { - Retirada do leite das doadoras (ordenha); } \\
\text { - Inserir o composto em um recipiente, conservá-lo em caixa térmica } \\
\quad \text { e transportá-lo até a estrutura física para realizar testes de }\end{array}$} \\
\hline
\end{tabular}




\begin{tabular}{|c|c|c|}
\hline & $\begin{array}{l}\text { qualidade no composto e, ca } \\
\text { realizar a pasteurização; } \\
\text { - Etiquetar os frascos de leite } \\
\text { frascos do freezer de leite cr } \\
\text { - } \text { Armazenar os frascos em fre } \\
\text { o leite cru encontra-se na fre } \\
\text { trás (pois, geralmente, são o } \\
\text { - Anotar as etiquetas em cade } \\
\text { responsável possa controlar } \\
\text { vencimento do leite cru, qua }\end{array}$ & $\begin{array}{l}\text { o seja aprovado no teste de qualidade, } \\
\text { om etiquetas específicas para os } \\
\text { e os frascos dos leites pasteurizados; } \\
\text { ezers, tendo um padrão de estocagem: } \\
\text { nte e o leite pasteurizado no espaço de } \\
\text { mais antigos); } \\
\text { nos, para que seja possível que a } \\
\text { s datas de validade tanto de } \\
\text { tto à validade do leite já pasteurizado. }\end{array}$ \\
\hline $\begin{array}{l}\text { Resposta à } \\
\text { pergunta 5: }\end{array}$ & $\begin{array}{l}\text { Ocorre somente o tipo de } \\
\text { manutenção corretiva, que } \\
\text { acontece somente quando algum } \\
\text { aparelho presente na estrutura } \\
\text { física do banco de leite quebra. } \\
\text { Durante a manutenção, se preciso, } \\
\text { os frascos de leite são realocados } \\
\text { para outras máquinas. }\end{array}$ & $\begin{array}{l}\text { São feitos tipos de manutenção: a } \\
\text { preventiva (que ocorre diariamente a } \\
\text { fim de prevenir defeitos nas } \\
\text { máquinas) e a manutenção corretiva } \\
\text { (dá-se quando alguma máquina } \\
\text { apresenta defeito). Durante a } \\
\text { manutenção, se preciso, os frascos de } \\
\text { leite são realocados para outras } \\
\text { máquinas. }\end{array}$ \\
\hline $\begin{array}{l}\text { Resposta à } \\
\text { pergunta 6: }\end{array}$ & $\begin{array}{l}\text { "É necessário que pelo menos uma } \\
\text { pessoa esteja trabalhando no } \\
\text { banco de leite enquanto ele está } \\
\text { aberto". }\end{array}$ & $\begin{array}{l}\text { "Precisamos que pelo menos três } \\
\text { pessoas estejam presentes nos } \\
\text { bancos de leite durante o seu } \\
\text { funcionamento para realizar os } \\
\text { processos de coleta e pasteurização". }\end{array}$ \\
\hline $\begin{array}{l}\text { Resposta à } \\
\text { pergunta 7: }\end{array}$ & \multicolumn{2}{|c|}{$\begin{array}{l}\text { O banco de leite não é de livre acesso, as responsáveis pelo manuseio dos } \\
\text { frascos são as técnicas de enfermagem, que estão familiarizadas, } \\
\text { conhecem o processo e são aptas a exercer tal função. O único processo } \\
\text { que é permitido ser efetuado por outros funcionários é o transporte dos } \\
\text { frascos de leite dentro da instituição. As técnicas de enfermagem preparam }\end{array}$} \\
\hline
\end{tabular}




\begin{tabular}{|c|c|c|}
\hline & \multicolumn{2}{|c|}{$\begin{array}{l}\text { os frascos, que serão disponibilizados, em questão de quantidade e outros } \\
\text { funcionários podem transportá-los para outro setor. }\end{array}$} \\
\hline $\begin{array}{l}\text { Resposta à } \\
\text { pergunta 8: }\end{array}$ & $\begin{array}{l}\text { Foram encontrados problemas de } \\
\text { estrutura física como: falta de } \\
\text { manutenção preventiva dos freezers } \\
\text { e o funcionamento do banco de } \\
\text { forma improvisada e manual - o } \\
\text { que torna a gestão, por vezes, } \\
\text { ineficiente. E também a falta de um } \\
\text { sistema informatizado para a gestão } \\
\text { do banco de leite de forma } \\
\text { eficiente. }\end{array}$ & $\begin{array}{l}\text { "Existe a ausência de funcionários no } \\
\text { banco de leite, pois ficam em média } \\
\text { duas ou três pessoas cuidando do } \\
\text { banco de leite, sendo que a demanda } \\
\text { por funcionários é maior que o que } \\
\text { temos". Também é possível destacar } \\
\text { a falta de um sistema computacional } \\
\text { informatizado e o espaço físico se } \\
\text { mostra insuficiente para atender à } \\
\text { demanda. }\end{array}$ \\
\hline $\begin{array}{l}\text { Resposta à } \\
\text { pergunta 9: }\end{array}$ & \multicolumn{2}{|c|}{$\begin{array}{l}\text { Nas duas maternidades, é notória a necessidade de um software de gestão, } \\
\text { já que todos os processos documentais acontecem de forma manual - com } \\
\text { papéis e fichas de registro. Ou seja, não utilizam de nenhum sistema } \\
\text { tecnológico para a gestão - o que, de acordo com os responsáveis pelos } \\
\text { bancos de leite, se mostra um problema em questão de dinamicidade e } \\
\text { praticidade da gestão. }\end{array}$} \\
\hline
\end{tabular}

Fonte: Autores, 2019.

Observou-se que, nas duas maternidades visitadas, a demanda por leite se mostra maior que a quantidade coletada, isso ocorre principalmente na Maternidade Escola Januário Cicco, que possui uma demanda diária de 8 a 9 litros de leite para uso próprio da instituição e ainda é responsável por distribuir o leite humano obtido para outras maternidades, porém, só são coletados, em média, 6 litros por dia - o que demonstra um déficit no cumprimento de demanda.

Existem duas vertentes em relação às manutenções praticadas nas maternidades: a manutenção preventiva (ocorre para que o problema não venha a acontecer) e a manutenção corretiva (que acontece depois da ocorrência de um problema, ela transcorre para que a máquina possa voltar a funcionar novamente). O banco de leite do Hospital Geral do Santa Catarina, diferente da Maternidade Escola Januário Cicco, não efetua a manutenção preventiva, somente a corretiva 
- e isso é problema, uma vez que aumenta a probabilidade de alguma máquina apresentar falha operacional.

Um grave problema evidenciado - que afeta principalmente a Maternidade Escola Januário Cicco (pelo fato de não conseguir cumprir a demanda frequentemente) - é a escassez de funcionários trabalhando diretamente nos banco de leite, pois, quanto menor a quantidade de funcionários, menos leite pode ser coletado e, logicamente, menos material será disponibilizado para a distribuição.

Contudo, o maior problema constatado nas maternidades foi a falta de um sistema informatizado para auxiliar e dinamizar processos, em razão de o meio utilizado para gerir os bancos de leite ainda serem arcaicos. As enfermeiras responsáveis pelo setor registram em cadernos dados como: a quantidade de leite no estoque, a validade do leite, a destinação do composto, dados a respeito das doadoras etc.

Portanto, a ausência de um sistema informatizado faz os processos serem mais lentos e menos eficientes, pois se os processos listados fossem efetuados através de um software a gestão dos bancos de leite poderia ter mais dinamicidade e teriam uma otimização do tempo de realização das atividades de registro e que envolvem documentação. Além do mais, a gestão seria mais eficiente, uma vez que poderiam dar baixa do estoque mais rapidamente e de uma forma mais simples e menos passível de erro do que a forma administrativa atual.

\section{Conclusão}

Diante as análises feitas nas maternidades: Hospital Geral Santa Catarina e Maternidade Escola Januário Cicco, concluiu-se que ambas utilizam do método de estocagem PVPS (Primeiro que Vence, Primeiro que Sai) devido à perecibilidade do leite humano.

Com base no observado durante as visitas às maternidades, é evidente que o método de estocagem utilizado é o mais adequado ao processo de estocagem do leite, pois atende às particularidades da substância. Todavia, os processos realizados nos bancos de leite - da coleta à distribuição do composto - não se mostram eficazes, pelo fato de que todos os processos que envolvem registro e documentação serem manuais e as maternidades ainda utilizarem o mesmo método de gestão desde a fundação - as maternidades entrevistadas foram fundadas ainda no século XX.

Também foi possível perceber que a quantidade de funcionários utilizados para cuidar dos bancos de leite nas instituições é insuficiente para uma gestão adequada (e, devido à alta demanda, a instituição que mais se prejudica com esse fato é a Maternidade Escola Januário 
Cicco), fator que atrasa os processos e compromete o funcionamento e eficiência dos bancos de leite.

Uma possível solução para a problemática da escassez de funcionários seria o uso de um sistema de recompensa. Tal sistema consistiria em fornecer uma recompensa financeira para os interessados em participar do setor e receber o treinamento necessário para atuar nele. Os funcionários interessados teriam uma escala diferenciada, tendo que se dividir entre a sua atividade original e a exercida nos bancos de leite, que também teria uma escala diferenciada com cada dia da semana tendo pessoas diferentes responsáveis por ele (para não gerar um déficit tão grande na instituição).

Logo, cabe reconhecer a importância da utilização de um software para assessorar a gestão dos bancos de leite, dado que a aplicação do software permite uma maior praticidade e dinamicidade na gestão, minimizando possíveis falhas operacionais nos processos de registro e documentação. Além disso, implementar um modelo de recompensa para os funcionários que participam do setor também é uma medida importante para melhorar o departamento, a fim de aumentá-lo e torná-lo mais eficiente e eficaz, focando na melhoria do processo. Esse método poderia ser aplicado como medida emergencial para substituir a contratação imediata de funcionários da área da saúde - pois, nesse caso, aumentar o quadro de funcionários é um processo longo e burocrático, já que se trata de órgãos públicos.

Portanto, diante da problemática supracitada, este estudo tem como proposição pesquisas mais detalhadas acerca da implementação de um Sistema de Informação para auxiliar a gestão dos bancos de leite das maternidades visitadas e da implementação do sistema de recompensas dos funcionários das maternidades para obter-se uma regulação do quadro de funcionários. Ademais, é fundamental que tal SI seja atualizado com informações gerais sobre o banco de leite da maternidade a que pertence, incluindo a grade de funcionários, para assim otimizar tempo, melhorar os processos logísticos e conseguir uma melhor gestão dos bancos.

\section{Referências}

ALMEIDA, Marcelo Cavalcanti. Auditoria: um curso moderno e completo. 7. ed. São Paulo: Atlas, 2010.

BALlOU, Ronald H. Logística Empresarial: Transporte, Administração de Materiais e Distribuição Física / Ronald H. Ballou; tradução Hugo T. Y. Yoshizaki - São Paulo: Atlas, 1993. 
DIAS, Marco Aurélio Pereira. Administração de materiais: uma abordagem logística. - 5. ed. - São Paulo: Atlas, 2010.

FERNANDES, José Carlos de F. Administração de material um enfoque sistêmico. 2 ed. Rio de Janeiro: Livros Técnicos e Científicos, 1984.

GONÇALVES, Paulo Sérgio. Administração de Materiais: obtendo vantagens competitivas. Rio de Janeiro: Elsevier, 2004.

MADEIRA, Márcia; FERRÃO, Maria Eliza Marti. Alimentos conforme a lei. São Paulo: Manole Biomedicina, 2002.

MARCO AURÉLIO P. DIAS, Administração de materiais, uma abordagem logística. São Paulo, Editora ATLAS S.A. 2015.

MOREIRA, Daniel Augusto. Administração da Produção e Operações. São Paulo: Pioneira Thomson Learning, 1996.

PATRUS (Transportes urgentes), 6 Métodos de gestão de estoque que a sua empresa precisa conhecer. Disponível em: <http://www.patrus.com.br/blogpatrus/?p=54>.

POZO, H. Administração de recursos materiais e Patrimoniais: uma abordagem logística. São Paulo: Atlas, 2001.

SALVETTI, Lucas Vieceli. Estudo e implantação da gestão de estoques em uma empresa do ramo supermercadista localizada no litoral Sul de Santa Catarina. 2012.

TEMPLUM, PEPS, PVPS e a qualidade integrada ao estoque. Disponível em: <https://certificacaoiso.com.br/qualidade-na-pratica-peps-e-pvps-e-a-qualidade-integrada-ao-estoque/>.

TUASAÚDE, 10 Benefícios para a amamentação. Disponível em: <https://www.tuasaude.com/beneficios-doleite-materno-para-o-bebe/>.

VAGO, F. R. M., Veloso, C., do Couto, J. M., Lara, J. E., Fagundes, A. F. A., \& de Oliveira Sampaio, D. (2013). A importância do gerenciamento de estoque por meio da ferramenta curva ABC. Revista Sociais e Humanas, 26(3), 638-655. 